\title{
Hibridismo e Fragmentação: a junção de linguagens artísticas na montagem do espetáculo Enquanto Dure
}

Hybridism and Fragmentation:the mix of artisticlanguages in the composition of the spectacle Enquanto Dure

Saulo Germano Sales Dallago ${ }^{1}$ 


\section{Resumo}

O Este estudo tem por objetivo analisar o processo de criação do espetáculo Enquanto Dure, realizado na cidade de Goiânia no ano de 2015, a partir de dois prismas principais: por um lado, a adaptação realizada do conto de Murilo Rubião, intitulado "Três Nomes de Godofredo", para a cena dramática, a partir dos processos de ensaio e criação teatral em conjunto com os três diretores da montagem; e, por outro, da inter-relação entre as diferentes linguagens artísticas elencadas para a produção da peça (o teatro, a dança e o audiovisual), permitindo o advento de uma composição estética híbrida, partindo da história do personagem principal do conto, e da fragmentação de sua identidade, que deu origem à montagem.

Palavras-chave: Teatro contemporâneo; linguagens híbridas

\section{Abstract}

This study aims to analyze the process of creating the spectacle "While Keep", held in the city of Goiânia in the year 2015, from two main prisms: on the one hand, the adaptation made of the story by Murilo Rubião, entitled "Three Names of Godofredo ", for the dramatic scene, from the processes of rehearsal and theatrical creation together with the three directors of the assembly; And on the other hand, the interrelationship between the different artistic languages listed for the production of the play (theater, dance and audiovisual), allowing the advent of a hybrid aesthetic composition, starting from the story of the main character of the story, and the fragmentation of his identity, which gave rise to the assemblage.

Keywords: Contemporary theatre; linguagens híbridas 
É inegável, no panorama da arte atual e, especificamente, do teatro, o crescente diálogo instituído entre múltiplas linguagens e meios no estabelecimento de matrizes criativas para a composição de espetáculos. Seja através da literatura, cujos contos, poesias e romances, não necessariamente elaborados para serem representados (como a parte dramática desta mesma linguagem) mas ganhando adaptações e ajustes para tal; ou da música, deixando cada vez mais de ser apenas parte acessória no fenômeno teatral e engajando-se enquanto elemento propulsor de encenações; da dança que, como arte do corpo, sempre manteve uma proximidade da arte da representação mas, em tempos atuais, imiscui-se de tal forma com a outra que chegou a gerar o advento de uma nova nomenclatura para designar espetáculos que partem desta premissa (dança-teatro); das artes visuais, fornecendo inspiração e impulsos para o desenvolvimento de cenas e performances; e, finalmente, das consideradas artes técnicas, como a fotografia e o cinema, vistas em tempos idos como meros instrumentos para registro da atuação viva e pulsante, passando na contemporaneidade a se vincular numa perspectiva multi-midial como componente intrínseco da arte da representação.

Tendo em vista esta discussão estabelecida no campo das artes, principalmente a partir da segunda metade do século XX e com especial força neste início de século $\mathrm{XXI}$, o projeto de montagem teatral intitulado Triunvirato foi proposto e aprovado junto ao Fundo de Arte e Cultura de Goiás 2013, visando constituir-se enquanto experiência de criação contemporânea híbrida, onde a literatura e o teatro dariam margem à participação de outras formas estéticas. Embora a proposta apresentada tivesse forte ligação com a arte contemporânea, a nomenclatura escolhida para o projeto teve suas origens em tempos bastante longínquos: segundo nos conta a história, o nome Triunvirato advém de uma associação política em que três homens exercem o poder em igualdade.

A escolha da nomenclatura que batizou o projeto teve por objetivo estabelecer, na criação do espetáculo, uma associação artística igualitária entre três diretores: um diretor de teatro, um diretor de dança e um diretor de audiovisual. Partindo de olhares e experiências diversas, estabelecendo assim a inter-relação entre diferentes linguagens artísticas no espetáculo, este triunvirato estético, num processo colaborativo, buscaria adaptar a literatura de Murilo Rubião para o palco. Neste sentido, o espetáculo seria gerado a partir de diálogos híbridos, instalando-se enquanto produção artística no intervalo criado pelo entrecruzamento de dança, teatro e vídeo vídeo/dança, vídeo/performance, dança/teatro. Todavia, a palavra "Triunvirato" também possui outra forte ligação com esta produção: o conto literário que dá origem a este processo, Três Nomes de Godofredo, obra do escritor mineiro Murilo Rubião, um dos maiores representantes da literatura fantástica brasileira. A história tem por protagonista o personagem Godofredo que, a partir do encontro com uma mulher em um jantar, acaba por ter desvelado diante de si seu próprio passado e três diferentes nomes que possuiu: Godofredo, João de Deus e Robério (Rubião, 2010). Assim, além da discussão sobre a hibridização artística, também é parte intrínseca da origem desta montagem a fragmentação da personalidade do sujeito, múltiplo e contraditório, graças às já apontadas características do mundo contemporâneo.

O processo de construção do espetáculo iniciou-se em dezembro de 2014 e 
culminou na estreia da peça intitulada Enquanto Dure, em abril de 2015. Os primeiros contatos entre os atores (um casal, sendo o próprio autor deste artigo e a atriz Andreydsa Borges) e os diretores (Alexandre Nunes, diretor teatral; Kleber Damaso, diretor coreográfico; Wesley Martins, diretor audiovisual) se deram a partir da leitura do texto, buscando traçar um roteiro de cenas ou momentos do espetáculo que conseguissem transmitir ao espectador as peripécias da trama de Rubião. Logo de início, dividiu-se o conto em quatro grandes cenas, as quais descrevo a seguir: 1) a cena inicial, do encontro do casal no restaurante; 2 ) a cena do convívio do casal em casa, rotina; 3 ) o retorno ao restaurante após o marido ter assassinado a esposa e o reencontro com outra versão dela; 4) a cena final, em casa, onde ele a reencontra ainda em outra versão e a mata novamente, e logo em seguida se depara com mais uma versão da mesma, não mais sua esposa, mas agora sua noiva (Rubião, 2010).

O diretor Alexandre Nunes propôs que, a partir desta divisão, retirássemos do texto todos os diálogos entre os personagens para que, a partir dele, traçássemos um roteiro cênico, no qual estes diálogos seriam a base propulsora da encenação, tendo como complemento posterior as partes coreográficas e audiovisuais, a partir da colaboração artística dos outros diretores daquele Triunvirato. Assim, coube inicialmente a Nunes a estruturação geral do espetáculo, na qual foram definidas como seriam construídos os diferentes momentos da trama.

Conforme afirma Alexandre Mate (2011, p. 94):

\begin{abstract}
No texto teatral clássico, invariavelmente, além da concisão do tempo e das ações, a personagem fala por si (não há intermediação de um narrador); entretanto, nas formas populares, infantis e épicas, a narração, em boa parte das vezes, é intrínseca e constitutiva da forma. Do mesmo modo, se a forma clássica e hegemônica do drama (fundamentada no tratamento ilusionista) recria a cena colada ao real, como se fosse a própria realidade, em outros gêneros, o cenário, ou os adereços não necessitam de qualquer relação ilusionista com a cena, podem ser funcionais, absolutamente simbólicos. Dessa forma, o ONDE é importante, mas não a sua criação na forma de cenário. O espaço pode ser "mostrado" por meio da fala, de projeção videográfica, de desenhos esquemáticos...
\end{abstract}

Partindo deste pressuposto em relação a cenografia, a equipe artística optou por desenvolver um cenário híbrido e funcional, que pudesse significar vários locais e objetos de acordo com as mudanças propostas pela dramaturgia. Para compor, então, a materialidade da cena, foram escolhidos cubos de madeira e espuma cobertos com couro sintético (popularmente conhecidos como "puffs"), e foram dispostos simetricamente 16 destes cubos pelo espaço, sempre em pares. Além disso, um pano branco para as projeções foi disposto como rotunda, com duas pernas da mesma cor, em harmonia com a coloração dos cubos (bege claros), transformando o espaço cênico numa espécie de vazio simétrico, cúbico e de cor clara. 


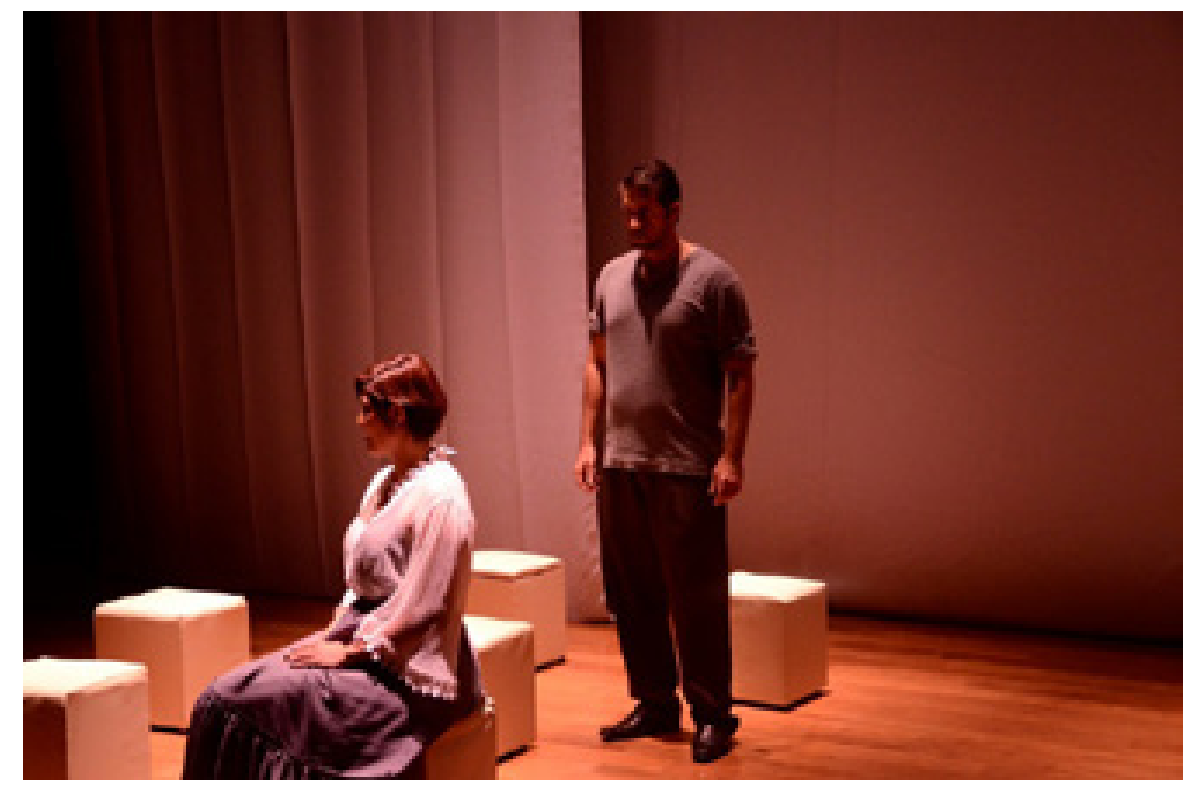

Imagem 1 - Cena inicial do espetáculo Enquanto Dure. Foto: Fabricia Vilarinho

A cena inicial do espetáculo, como já descrito acima, passa-se num restaurante, onde no conto de Rubião o personagem principal, Godofredo, narra em primeira pessoa o encontro com uma mulher que afirma ser sua esposa. A direção cênica optou por estabelecer um jogo inicial para, corporalmente, construir a relação díspar entre o casal relatada por Rubião no conto: a estranheza do homem, por não reconhecer a mulher que se senta próximo a ele e demonstra uma certa intimidade, e a naturalidade da personagem feminina, agindo como se conhecesse o estranho à sua frente. Assim, enquanto o homem age como se não conhecesse a mulher, ela o olha fixamente com um leve sorriso nos lábios. Incomodado, ele troca de lugar, levando consigo seu prato, talheres e copo (invisíveis, porém cenicamente críveis, uma vez que o mesmo fisicaliza estes objetos através de seus gestos, como se realmente jantasse) por várias vezes, sempre sendo perseguido por ela. Num dado momento, ele desiste de levantar-se e, ao olhá-la, subitamente tem uma recordação e inicia o diálogo perguntando se a convidou para jantar.

É importante ressaltar que, no texto de Rubião, o personagem-narrador Godofredo troca de lugar no restaurante apenas por uma vez - porém, esta única ação, do ponto de vista da dramaturgia da cena, não pareceu suficiente para transmitir ao espectador a situação constrangedora do mesmo, e por esta razão optou-se por transformar a troca de lugar numa espécie de perseguição por parte da mulher desconhecida. Entretanto, esta modificação, ou antes esta multiplicação da ação, conjuga-se sobremaneira com o diálogo posterior que se segue, onde Godofredo descobre que a mulher é sua esposa, da qual ele não se recorda, o que justifica as atitudes antagônicas por parte de um e de outro.

Conforme afirma Sinisterra, abordando a questão da adaptação literária para dramaturgia teatral:

Não podemos pensar que, só porque o romance ou o conto já tenham por si uma boa estrutura narrativa, sua estrutura dramática esteja garantida. É preciso recolocar, em termos dramáticos, os personagens, diálogos, a progressividade e a própria noção de ação dramática, que não é equivalente à trama ou argumento, 
e que, como sabemos, é uma coisa difícil de definir e de apreender. (Sinisterra, 2016, p. 122 e 123)

Assim sendo, mesmo nos mantendo fiéis ao roteiro narrativo do conto, muitos elementos surgiram para reforçar a ação dramática da história, tanto que, como veremos, a partir da metade do conto, o espetáculo optou por uma linha bastante diferente daquela dada por Rubião em seu desfecho literário (a cena 4, descrita anteriormente), transformando o final da peça numa explosão de imagens cênicas ao espectador bastante diversa daquilo que o leitor do conto teria quando da finalização da leitura do mesmo.

Antes, porém, de chegarmos até o desfecho da encenação, é interessante que abordemos também as outras linguagens artísticas presentes nesta obra híbrida, já descritas anteriormente quando da concepção do projeto Triunvirato: a dança e o audiovisual. Quanto à primeira, é interessante notarmos que os limites entre o teatro e a dança, em algumas obras contemporâneas, são bastante tênues, e que neste sentido tornou-se necessário um profundo diálogo entre os diretores cênico e coreográfico, pois o gesto, a ação física, a expressão corporal são elementos comuns às duas artes da cena.

Embora não se possa afirmar que o espetáculo Enquanto Dure possa ser classificado enquanto dança-teatro, é inegável que as duas artes são o fundamento criativo principal a partir do qual a literatura tomou corpo e foi concretizada em cena, tendo sido cada sequência de ações físicas do casal de atores protagonistas desenhada e demarcada por ambos diretores, de teatro e dança, da montagem. Sobre a dança-teatro e seus fundamentos, que podem ser tomados como base para a construção da encenação em questão, podemos afirmar que

É nesse ponto que reside uma das qualidades básicas da dança-teatro. É claro que a intenção do movimento é fundamental, porém, ela está sempre ligada a uma consciência formal, que possibilita que a escrita dramatúrgica corporal não se perca. Cada detalhe do movimento tem de ser claro, pois uma articulação de tornozelo, uma torção de cintura ou uma inclinação de cabeça imprecisa ou diferente pode mudar o sentido de toda uma sequência corporal. (Caldeira, 2010, p. 126)

A cena do espetáculo que possivelmente mais se enquadre na categoria de dança-teatro é uma coreografia executada pelo casal na segunda parte ou grande cena da montagem (a rotina do casal em sua residência). Após acordarem e tomarem café, ambos se dirigem a um canto da casa e, enquanto ela fisicaliza a ação de costurar, ele abre um jornal e começa a recitar um poema (o Soneto da Fidelidade, de Vinicius de Moraes). Ao longo da récita do poema, uma trilha sonora adentra a cena e a personagem feminina abandona sua ação de costurar, levanta-se e inicia uma espécie de dança com sua camisola, a qual passa a ser acompanhada pelo personagem masculino assim que se encerra poema. Esta coreografia, quando de sua concepção, foi imaginada para simbolizar o ato sexual de ambos e, para isso, idealizou-se como signo da penetração o entrar e sair dos corpos nos figurinos um do outro, transformando assim a ação cênica numa dança do acasalamento poética e sutil. Vale ressaltar que esta ideia coreográfica só foi possível ser realizada graças ao diretor de arte do espetáculo, Guilherme de Oliveira, responsável por cenário, figurinos e adereços, que 
visando atender as ideias dos diretores concebeu e executou figurinos folgados, com mangas e aberturas amplas, além de tecidos elásticos.

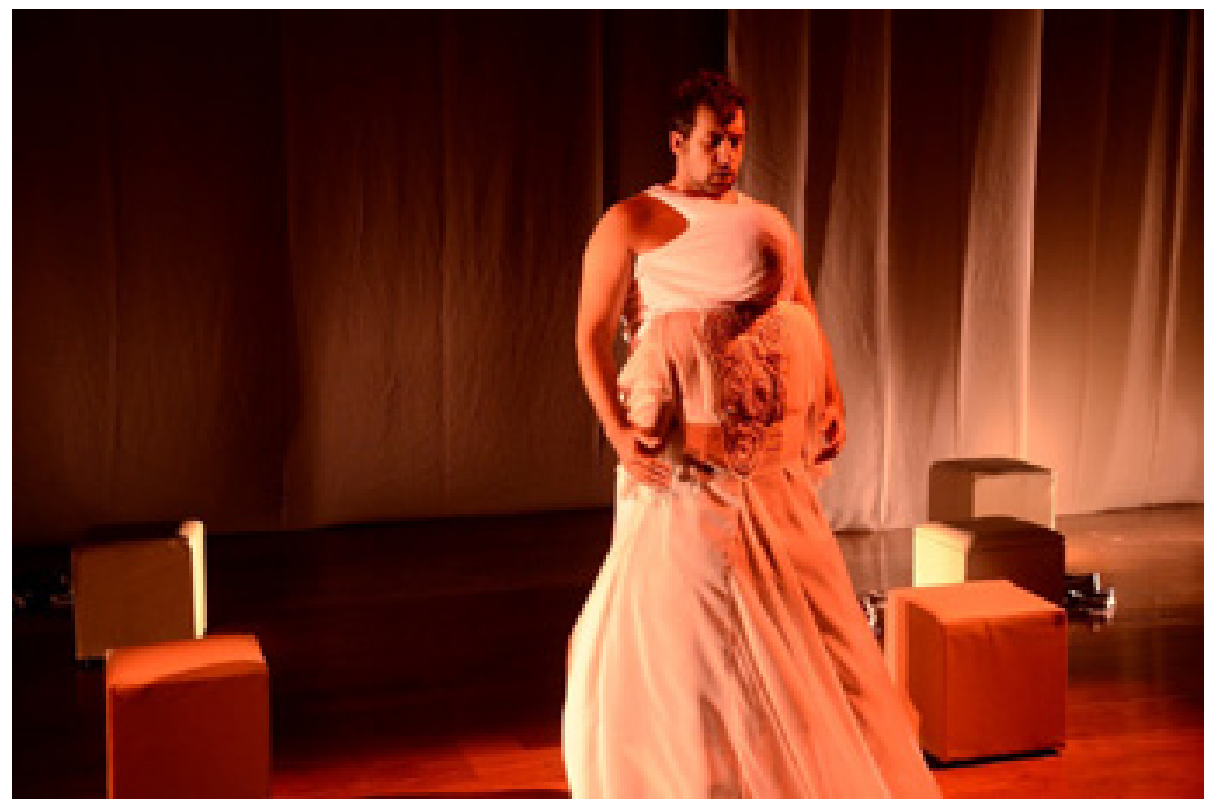

Imagem 2 - Cena coreográfica do espetáculo Enquanto Dure. Foto: Fabricia Vilarinho

Em relação ao audiovisual, na decupagem das cenas, foram elencados 3 momentos em que o vídeo tomaria frente na narrativa do enredo, sendo elas: a) o caminho do casal entre as cenas 1 e 2, ou seja, do restaurante para a casa; b) uma cena retirada de outro texto teatral, logo após o casal adormecer na sequência da já descrita coreografia; c) logo após o assassinato da mulher, uma cena que demonstrasse o personagem masculino sendo torturando pelo feminino. A cena - a - diz respeito à transição do casal, após o diálogo no restaurante, para a casa. A cena mostra ambos em uma rua, de mãos dadas, e num segundo momento dentro de um elevador. A cada andar alcançado (são 5 ao todo), a personagem feminina aparece com um figurino diferente (num andar, inclusive, ela é substituída por um manequim), até o andar final. Embora esta cena fosse uma continuação da ação teatral, tendo em sua sequência os atores voltando à cena como se adentrassem sua casa, este jogo de troca de figurinos serviu como um tipo de adiantamento do que aconteceria ao longo do espetáculo, que teria também em seu desenrolar algumas trocas de roupa (e de personalidade) por parte da mulher, como veremos.

A segunda cena em audiovisual - b - é um excerto do texto teatral $A$ Cantora Careca (1949), de Eugene Ionesco, que foi utilizada por sua semelhança com a temática do conto de Murilo Rubião. Trata-se do diálogo entre o casal Martin, no qual ambos começam a perceber enormes coincidências entre suas vidas e rotinas e, ao final, recordam-se ser marido e mulher. Vale frisar que este é o único dos três vídeos da peça em que aparecem falas, diálogos entre os personagens, além de ser o mais longo. No momento do espetáculo em que o vídeo é introduzido, as personagens acabaram de realizar a coreografia anteriormente descrita e, finalizada a mesma, dirigem-se para um sofá simbólico (representado por dois puffs), onde adormecem após o marido ligar uma imaginária TV. A abertura do vídeo se dá como o efeito de uma 
televisão sendo sintonizada, até o surgimento da imagem; ao final do vídeo, a mesma estética é utilizada, demonstrando a imagem perdendo novamente a sintonia. $O$ cenário foi planejado contendo apenas um jogo de chá para duas pessoas, uma mesa com tampo de vidro e duas banquetas. O fundo foi totalmente anulado com a falta de iluminação. Essa concepção foi planejada para que o espectador não pudesse identificar a temporalidade ou a veracidade do que é retratado na tela, além de carregar as imagens com um clima de mistério e dúvida. Tanto o ator como a atriz estão vestidos com ternos, o que traz a imagem de figuras homogêneas. Ao final do vídeo, os atores despertam em cena, e retomam o espetáculo a partir da rotina do casal.

Já a cena - c -, terceira e última parte audiovisual do espetáculo, ocorre após o assassinato da esposa pelo marido, seguido pelo ocultamento do corpo da mesma, arrastado por ele, e já coberto pelo pano que fora seu vestido no início da peça, para fora do palco. O vídeo é projetado simultaneamente ao retorno do personagem masculino à cena, e acontece enquanto o mesmo vai vestindo seu figurino do início do espetáculo (importante frisar que toda a cena 2, da rotina do casal em sua residência, é realizada com ambos vestindo roupas de dormir, os já descritos figurinos "largos" e "elásticos"). O vídeo mostra várias sessões de tortura da personagem feminina para com o personagem masculino, como enforcamento, asfixia e chicotadas, durante as quais a esposa demonstra um enorme prazer pelo sadomasoquismo operado.

É essencial abordar as diferentes formas como o audiovisual adentrou a cena dramática, nestes 3 momentos, como diferentes relações estabelecidas com o espetáculo cênico em andamento. No primeiro vídeo (a), a linguagem adotada pelo audiovisual é diretamente ligada à continuidade da cena, apresentando os personagens com os mesmos figurinos e ligando a cena inicial do espetáculo, no restaurante, à cena seguinte, na residência de ambos, constituindo-se assim como um plano de "realidade" (em aspas pois, como já dito, há a introdução do elemento surreal na troca de figurino pela personagem feminina a cada andar). A cena audiovisual (b) traz uma dimensão onírica, do plano dos sonhos, uma vez que acontece enquanto os personagens, no palco, encontram-se adormecidos. Além disso, os figurinos, as imagens em preto e branco, o espaço atemporal e sem localização definida, assim como o diálogo com referências a um contexto britânico (cidades como Londres e Manchester são citadas) reforçam a tese da "não realidade" da cena; e, assim como o vídeo anterior, o (c) não se apresenta como uma continuação da cena, mesmo porque também como no (b) um dos personagens está presente no palco enquanto acontece a projeção (o homem, que se veste), porém, diferente da cena precedente, os personagens apresentam coerência nos figurinos, maquiagem e ações, além de cenário (os puffs são utilizados nesta cena), o que nos remete a imagens mentais não advindas da imaginação, mas sim da memória.

Realidade, alucinação e memória, como expressões da personalidade do sujeito, adentram então a cena dramática em diferentes trechos, mesclando a linguagem teatral com a audiovisual e revelando, através de distintos aspectos, a identidade fragmentada do personagem Godofredo - não só pelos diferentes nomes que assume ao longo do espetáculo (João de Deus e Robério são as outras alcunhas que a personagem feminina utiliza para se referir a ele) mas também pelos distintos traços de caráter que apresenta ao longo do espetáculo. Ora, devemos nos lembrar que, 
no início da história, Godofredo sequer lembra-se de ter uma esposa, um lar a dois, entre outros detalhes de seu passado - e é a partir desta busca pela memória que o personagem vai nos revelar mais informações sobre seu "eu"; a busca contínua por si mesmo, com os pés no presente e os olhos no passado.

A medida que transcorrem os diversos episódios que compõem a vida de alguém, o sujeito vai modificando permanentemente a identidade do "si mesmo", não só no que diz respeito a sua visão em relação ao futuro, mas também ao passado. Isto se refere a um processo contínuo mediante o qual cada pessoa reinterpreta a totalidade de sua existência, reconstrói o "si mesmo" a partir de sua atualidade. (Pinã, apud Díaz, 1999, p. 41)

Entretanto, Godofredo pode ser visto como a expressão máxima da descentralização do "eu", em sua tentativa desesperada de reencontrar o passado, acaba repetindo-o continuamente no presente. Acusado pela atual mulher, da qual não se lembra, já na primeira cena do espetáculo, de ter assassinado a primeira esposa, acaba por matar também a segunda e, ao sair da residência e refugiar-se novamente no restaurante, encontra a primeira esposa, que o chama pelo nome Robério e afirma que "não lhe virá o esquecimento" (Rubião, 2010). Neste momento deste estudo, aproximando-se de seu final, não podemos nos furtar a uma análise do desfecho do espetáculo, exemplar tanto do ponto de vista da discussão entre memória e identidade do sujeito, quanto em relação a transmutação da linguagem literária em linguagem cênica.

No conto de Rubião, nosso herói retorna novamente para casa após a discussão com a primeira esposa no restaurante acima relatada. Lá, encontra uma nova versão da mesma mulher (no conto todas possuem o mesmo rosto, com leves características diferentes) e a mata. Tão logo abandona seu corpo, reencontra ainda uma quarta versão da esposa que, desta vez, afirma ser apenas sua noiva, e que irão se mudar após o casamento para a cidade natal do mesmo (Rubião, 2010). Já no espetáculo, a direção optou por, após a cena do restaurante, estabelecer um jogo cênico de assassinato e ressurreição, no qual seria possível provocar na plateia distintas impressões e leituras sobre os acontecimentos e os personagens.

Ao sair do restaurante, o personagem Godofredo oculta-se fora do palco, enquanto a mulher retira o vestido e o guarda em um puff-baú (com tampa e fundo oco, no qual vários objetos são guardados/retirados ao longo do espetáculo). Godofredo retorna e a mata, repetindo a ação mais três vezes, e em cada uma dessas mortes a atriz utiliza sapatos diferentes (a cada vez que é morta, ela ressuscita e apanha novos sapatos no puff-baú) que, após, consumado cada homicídio, são retirados e dispostos pelo assassino em cima dos cubos, como objetos de fetiche, coleção. Após a última morte, o corpo da mulher é oculto pelo homem com os puffs, e ele sai de cena, deixando-a assassinada e oculta - mas, mais uma vez, ela torna à vida e se liberta da prisão, espalhando os puffs pelo palco e derrubando os sapatos que ele havia disposto em cima dos mesmos. Calmamente, ele retorna a cena, senta-se em um dos puffs e passa a mexer num aparelho celular imaginário. Ela, após observar por alguns instantes a ação dele, num acesso de fúria, atira vários puffs contra o marido, abandonando-o em seguida no caos de objetos dispersos pelo palco. Uma vez sozi- 
nho, ele passa a reorganizar sua coleção de sapatos/assassinatos, colocando um em cada puff e, ao final, retira mais sapatos ocultos em puffs baús, que podem simbolizar outras mulheres/outros assassinatos. O último sapato a ser retirado e disposto é exatamente o primeiro sapato usado pela esposa no espetáculo, de cor prata (todos os outros são pretos), que, após colocado no puff e observado por alguns instantes, é deixado solitário, mas em companhia dos outros sapatos na cena, exatamente no desfecho do espetáculo, permitindo ao espectador várias leituras simbólicas a partir deste ato final. Cada sapato/assassinato se liga a uma relação diferente, ou à várias fases da convivência com a mesma mulher? O personagem de fato é um assassino, ou as mortes são imaginárias? Quais são os reais traços de sua personalidade, de sua identidade?

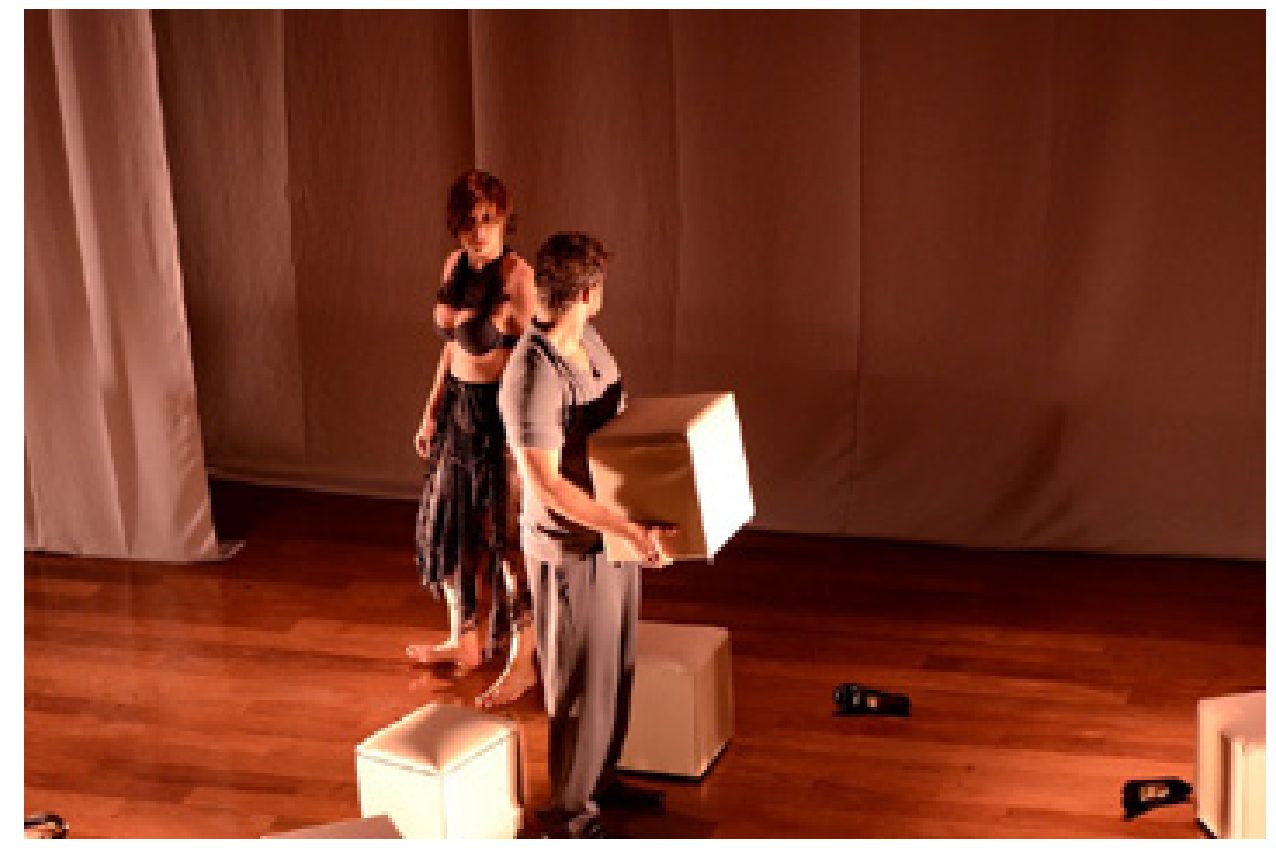

Imagem 3 - Cena final do espetáculo Enquanto Dure. Foto: Fabricia Vilarinho.

Para Stuart Hall (2014) a identidade é algo formado, ao longo do tempo, através de processos inconscientes, e não algo inato, existente na consciência do indivíduo no momento do nascimento. Existe sempre algo fantasiado sobre sua unidade: ela permanece sempre incompleta, está sempre "em processo", sempre "sendo formada". A identidade surge não tanto da plenitude da identidade que já está dentro de nós como indivíduos, mas de uma falta de inteireza que é "preenchida" a partir de nosso exterior. Sendo assim, o personagem Godofredo, fragmentado em sua personalidade, toma contato com suas diferentes identidades, seus diferentes "eus", a partir do contato com a figura de sua esposa, ou de suas diferentes esposas, conforme intepretação que se dê ao enredo da história. As diversas mortes, assim, parecem mais ligadas metaforicamente ao desaparecimento de traços do próprio assassino, ou de sua memória, se pensarmos as recordações enquanto formadoras de sua identidade.

A fragmentação da identidade do sujeito, no desfecho da montagem, converte-se na fragmentação do próprio espetáculo: dos assassinatos, das mulheres, dos puffs, dos sapatos como símbolos de diferentes memórias e identidades imaginadas sobre si mesmo. Quanto ao aspecto da linguagem performática propriamente dita, 
vale ainda ressaltar, mais uma vez relacionando a construção da dramaturgia cênica com a dança-teatro, que:

Quando se escreve, as palavras não escapam do papel, mas quando a escrita é com músculos e nervos, é preciso domínio e consciência total do desenho e da intenção dos movimentos, para que se possa repeti-los com precisão, como em qualquer dramaturgia encenada. (Caldeira, 2010, p. 128)

Portanto, podemos inferir, a partir de todas as informações descritas e discutidas, que o espetáculo Enquanto Dure, fruto do projeto "Triunvirato", alcançou enquanto realização cênica as ideias geradoras que impulsionaram sua concepção, abordando de forma surreal o relacionamento amoroso e colocando em evidência a fragmentação do sujeito a partir da busca pelo seu passado e pelo significado de sua história. Por outro lado, tendo como ponto de partida a inter-relação entre diferentes linguagens artísticas, viabilizou a adaptação de um conto literário para os palcos, através também do diálogo com as artes da dança e do vídeo, além do teatro propriamente dito

\section{Referências}

CALDEIRA, S. A Construção poética de Pina Bausch. Revista Poiésis, Rio de Janeiro: Editora da UFF, n. 16., p. 118-131, dez. 2010. Disponível em: http://www.poiesis.uff.br/PDF/poiesis16/Poiesis_16_ART_PinaBausch.pdf . Acesso em: 18 mai. 2017.

DÍAZ, Raul. Personaje e identidad narrativa: una aproximación metodológica. Revista Horizontes Antropológicos. Porto Alegre: ano 5, n 12, 1999.

HALL. S. A identidade cultural na pós-modernidade. Rio de Janeiro: Lamparina, 2014.

MATE, A. Uma proposta de adaptação de textos literários para a linguagem teatral: "Tudo certo como dois e dois são cinco". Caderno de formação: formação de professores didática dos conteúdos/Universidade Estadual Paulista. São Paulo: Cultura Acadêmica, 2011. Disponível em: http://www.acervodigital.unesp.br/bitstream/123456789/40547/1/Caderno_blc2_vol5_final.pdf . Acesso em: 18 mai. 2017.

RUBIÃO, M. Murilo Rubião - obra completa. São Paulo: Companhia das Letras, 2010.

SINISTERRA, J. S. Da literatura ao palco: dramaturgia de textos narrativos. São Paulo: É Realizações, 2016.

Recebido em:

03/07/2017

Aprovado em: 18/10/2017 